\title{
Students' Satisfaction and e-Learning Courses in Covid-19 Pandemic Era: A Case Study
}

\author{
Leila ERFANNIA ${ }^{\mathrm{a}, \mathrm{b}}$, Roxana SHARIFIAN ${ }^{\mathrm{c}}$, Azita YAZDANI ${ }^{\mathrm{b}, \mathrm{c}}$, \\ Aida SARSARSHAHI ${ }^{\mathrm{d}, 1}$, Rezvaneh RAHATI ${ }^{\mathrm{e}}$ and Saeedeh JAHANGIRI ${ }^{\mathrm{e}}$ \\ a Health Information Technology Department, Paramedical School, Zahedan \\ University of Medical Sciences, Zahedan, Iran \\ ${ }^{\mathrm{b}}$ Clinical Education Research Center, Shiraz University of Medical Sciences, Shiraz, \\ Iran \\ c School of Health Management and Information sciences, Health Human Resources \\ Research Center, Shiraz University of Medical Sciences, Shiraz, Iran \\ d Medical Equipment Department, Urmia University of Medical Sciences, Urmia, Iran \\ ${ }^{\mathrm{e}}$ Scientific research center, Zahedan University of Medical Sciences, Zahedan, Iran
}

\begin{abstract}
The present study is conducted to determine the status of e-learning, student satisfaction and the relationship between these two variables in Zahedan University of Medical Sciences (ZAUMS). According to a descriptive study, there was just a significant difference between the mean score of e-Learning experience and student satisfaction, and a positive correlation between the education level and student satisfaction. Also, there was a positive correlation between all variables of e-learning and student satisfaction The findings showed that the more capable learners were outcome of better educational content, stronger e-learning infrastructure, better support and assessment of e-learning quality, which ,in turn, resulted in the greater the students' satisfaction. As a result, the experiences from the evaluation of e-learning in the Covid-19 pandemic period may be regarded a good guide in improving the course during the Covid-19 pandemic, and also it can be considered a key factor in providing educations in the post-Covid-19 period.
\end{abstract}

Keywords. E-Learning, Satisfaction, Student, Covid-19 pandemic,

\section{Introduction}

With the outbreak of the cCovid-19 pandemic and the resulting restrictive measures such as quarantine and social distance, many people worldwide were forced to change their lifestyles and use online platforms for education, entertainment and work [1]. Before the Covid-19 pandemic outbreak, e-learning had been growing at a rate of $15.4 \%$ per year in educational institutions around the world without pressure from institutions or learners, followed with a dramatic boom with the occurrence of the Covid-19 pandemic [2].

Allegedly, Student attitude evaluation is one of the important methods of evaluation in the educational system [3]. A survey of students' views around the world about virtual

${ }^{1}$ Corresponding Author, Aida Sarsarshahi, Medical Equipment Department, Urmia University of Medical Sciences, Orjhans Street, Resalat Blvd, Urmia, IR Iran; E-mail: sarsarshahi81@gmail.com. 
education offered during the Covid-19 pandemic reveals two general views: The first group of students who have a positive attitude refer to easy access to educational resources at any time and any place, maximum coverage of education for a wide range of audience and more freedom to communicate with professors [3, 4]. However, those who had a negative attitude towards the virtual education point to their unwillingness to use, insufficient infrastructure and technology constraints, managerial and technical support, access problems such as Internet connection, mobile phone, and laptop ownership and usage costs as their most important challenges in using e-learning [5-7].

Hence, owing to the complexity of e-learning structure and evaluating e-learning, there is a need to consider students' perspectives and other components related to elearning structure at Zahedan University of Medical Sciences where all educational courses were offered through virtual education. Therefore, the purpose of this study was to determine the status (according 5 variable in present research) of virtual education, student satisfaction, and the relationship between these two variables.

\section{Methods}

The present study was a descriptive cross-sectional study in nature conducted at Zahedan University of Medical Sciences in 2021. Based on a simple random sampling method, 325 people were selected (Total number $=2150$ ) of whom 300 participated in the study. The research tool was a mixed questionnaire adapted from previous research and included three general sections [8]. The first part covered the demographic information of the respondents. The second part consisted of 33 questions about the status of elearning and included 5 dimensions of individual characteristics of the learner, educational content, infrastructure, support, and assessment. The third section encompassed 19 questions related to students' satisfaction with e-learning and consisted of five Likert scales from strongly agree to strongly disagree. The questionnaire was designed online and shared on educational platforms for students.

Descriptive and analytical statistical methods were used to analyze the data. Therefore, ANOVA and Pearson correlation tests were used to analyze the mean score and correlation between demographic variables and satisfaction, .Also, Pearson correlation test was used to analyze the correlation between the variables of e-learning status and students' satisfaction.

\section{Results}

Based on the findings, most of the participants were women (87.7\%). The highest mean age was 25 to 35 years. Also, $11.3 \%$ of the participants were students of health information technology. $74.7 \%$ of the participants had used the virtual education system for less than a year. Most people had a bachelor's degree (81.3\%). (Table 1). According to the comparison tests of the means, there was just a significant difference between the mean of e-Learning experience and student satisfaction $(\mathrm{P}$-value $=0.027, \mathrm{~T}$-score $=2.56)$. 
Table1. Frequency of demographic variables and statistical.

\begin{tabular}{lllll}
\hline Variable & Variable Category & $\begin{array}{l}\text { Frequency } \\
\mathbf{( \% )}\end{array}$ & Test & $\begin{array}{l}\text { P-Value } \\
\text { (T-score) }\end{array}$ \\
\hline Education Field & Health Information Technology & $34(11.3)$ & ANOVA & $0.950(0.93)$ \\
& Radiology & $32(10.7)$ & & \\
& Nursing & $27(9)$ & & \\
& Midwifery & $18(6)$ & & \\
& Anesthesia & $23(7.7)$ & & \\
& Medicine & $22(7.3)$ & & \\
& Environmental Health & $27(9)$ & & \\
\hline & Nutrition & $10(3.3)$ & & \\
& Physiotherapy & $15(5)$ & & \\
& Laboratory Sciences & $26(8.7)$ & & \\
& Professional Health & $14(4.7)$ & & \\
& Audiology & $3(1)$ & & \\
& Optometry & $9(3)$ & & \\
\hline E-Learning & Speech Therapy & $7(2.3)$ & & \\
Experience & $<1$ & $224(74.7)$ & ANOVA & \\
& $1-3$ & $62(20.7)$ & & \\
\hline Education Level & B.S & $14(4.7)$ & & \\
& M.S & $252(84)$ & ANOVA & $0.267(1.01)$ \\
\hline
\end{tabular}

Based on the results of Pearson correlation test; There was just a positive correlation between the education level and student satisfaction $(\mathrm{p}=0.049, \mathrm{~N}=300, \mathrm{r}=0.398)$, implying that the higher the level of education of students, the more satisfaction they show with virtual education. To evaluate the status of e-learning, five variables of learner individual characteristics, educational content, infrastructure, support, and assessment were used. To determine the relationship between these variables and student satisfaction, the Pearson correlation test was used. The results showed that there was a positive correlation between all variables and student satisfaction, the more capable learners, better educational content, stronger e-learning infrastructure, better support and assessment of e-learning quality, the greater the students' satisfaction. (Table 2).

Table2. Correlation between variables and students' satisfaction.

\begin{tabular}{llll}
\hline \multirow{2}{*}{ Variable } & \multicolumn{2}{l}{ Students Satisfaction } & \\
\cline { 2 - 4 } & $\mathbf{N}$ & Pearson correlation & Sig.(2-tailed) \\
\hline Learner Individual Characteristics & 300 & 0.508 & 0.000 \\
Educational Content & 300 & 0.445 & 0.000 \\
Infrastructure & 300 & 0.509 & 0.000 \\
Support & 300 & 0.517 & 0.000 \\
Evaluation & 300 & 0.569 & 0.000 \\
\hline
\end{tabular}

\section{Discussion}

The results of the present study showed that there was no significant difference between the mean of variables such as level of education, and level of student satisfaction. Diab's and Shahzad's study showed that a significant difference between the gender variable and the attitude towards virtual education during the Covid-19 pandemic [5, 9]. In the present study, there was a significant difference between the average experience of using the e-learning system and the level of satisfaction. However, these two variables did not 
correlate and in contrast, there was a direct and positive correlation between education level and satisfaction, which was consistent with the results of Diab`s research [5]. Students at ZAUMS were satisfied with the virtual education (Mean=99.10, Std.Dev=16.54) which was offered during the Covid-19 pandemic. They also considered virtual education as favorable and satisfactory. Two factors-i-e- ease of use and usefulness of working with the system, - were effective in students' intention to use virtual education [9]. Therefore, the development of e-learning based on easy and useful tools can be considered as one of the effective strategies of e-learning planners at universities [10]. In conclusion, the results of the present study showed that a set of factors involved in students' satisfaction such as learner ability, infrastructure, support, educational content, .As a result, evaluation can assess the status of virtual education and can serve as a model in future research. Accordingly, more attention should be paid to educational content and infrastructure improvement in software and hardware, support the virtual program by top management, e-learning programs evaluation. Using the results of this study and considering the effective factors, health informatics specialists will have a valuable consulting role in designing better e-courses as well as tools related to content production and evaluation. To sum up, experiences from the evaluation of elearning in the Covid-19 pandemic period, may act as a good guide in improving the course during the Covid-19 pandemic, and in the post-Covid-19 period.

\section{Acknowledgments}

The present study is adapted from a scholarly student research that was approved in scientific research center in Zahedan University of Medical Sciences with IR.ZAUMS.REC.1399.450 ethical code.

\section{References}

[1] Favale T, Soro F, Trevisan M, Drago I, Mellia M. Campus traffic and e-learning during covid-19 pandemic. Computer networks. 2020;176:107290.

[2] Alqahtani AY, Rajkhan AA. E-learning critical success factors during the covid-19 pandemic: A comprehensive analysis of e-learning managerial perspectives. Education sciences. 2020;10(9):216.

[3] Edelhauser E, Lupu-Dima L. Is romania prepared for elearning during the covid-19 pandemic? Sustainability. 2020;12(13):5438

[4] Khan MA, Nabi MK, Khojah M, Tahir M. Students' perception towards e-learning during covid-19 pandemic in india: An empirical study. Sustainability. 2021;13(1):57.

[5] Diab G, Elgahsh NF. E-learning during covid-19 pandemic: Obstacles faced nursing students and its effect on their attitudes while applying it. American Journal of Nursing. 2020;9(4):300-14.

[6] Aboagye E, Yawson JA, Appiah KN. Covid-19 and e-learning: The challenges of students in tertiary institutions. Social Education Research. 2021:1-8.

[7] Olum R, Atulinda L, Kigozi E, Nassozi DR, Mulekwa A, Bongomin F, et al. Medical education and elearning during covid-19 pandemic: Awareness, attitudes, preferences, and barriers among undergraduate medicine and nursing students at makerere university, uganda. Journal of Medical Education and Curricular Development. 2020;7:2382120520973212.

[8] Ismaili H, Rahmani SH, Kazemi A, Ali Ahmadi M. Evaluation of E-Learning of the virtual learning program from the student's point of view. Journal of Public Management Researches. 2016;9:203-22.

[9] Shahzad A, Hassan R, Aremu AY, Hussain A, Lodhi RN. Effects of covid-19 in e-learning on higher education institution students: The group comparison between male and female. Quality \& quantity. 2021;55(3):805-26.

[10] Vuorela M, Nummenmaa L. How undergraduate students meet a new learning environment? Computers in Human Behavior. 2004;20(6):763-77. 